\title{
Editorial
}

\author{
Bernard Perbal
}

Received: 2 February 2014 / Accepted: 2 February 2014 / Published online: 19 February 2014

(C) The International CCN Society 2014

On behalf of the editorial board of JCCS and of the whole production department at Springer, it is my pleasure to extend our very best wishes for 2014 to all our readers, occasional and regular.

With this coming new year, several important improvements will be instituted both for the Journal of Cell Communication and Signaling (JCCS), the official organ of the International CCN Society (ICCNS), and the ICCNS itself.

\section{The journal of cell communication and signaling}

The first 2014 issue of JCCS reflects the organizational changes that were introduced and reported in my previous editorial ${ }^{1}$ in order to foster the scope and readership of JCCS.

Together with the introduction of the new sections in JCCS, and to achieve the highest publication quality, I have also asked our group to revisit the composition of the JCCS editorial board. New editors with the appropriate expertise to help

\footnotetext{
${ }^{1}$ As a reminder, JCCS was launched in 2007 after the editorial board and myself, as editor in chief, had decided to stop working with BMC who had published since 2003 a journal called Cell Communication and Signaling(CCS) created upon my initiative after I had suggested to BMC in 2002, both the name of the journal, the scientific topic and the name of the email address.

Following the publication of JCCS first issue in 2007, BMC decided to reuse the CCS acronym that I had created, and appointed a new editorial board to run the same type of scientific publication, without even informing me.

Although this decision raises legal issues which are still pending, BMC continued publishing CCS on line, and therefore created a confusion between the two journals CCS and JCCS.
}

\section{B. Perbal $(\square)$}

International CCN Society, Nice, France

e-mail: bperbal@gmail.com consolidate JCCS as a reference publication in the field of cellular communication and signaling were considered. Thanks to L. Lau suggestions, I was pleased to invite the following colleagues who kindly accepted to join the editorial board of JCCS.

Let me welcome J. E. Murphy-Ulrich (UAB School of Medicine, Birmingham) whose research focuses on the role of thrombospondin in response to injury and stress; R. Brekken (UT Southwestern, Dallas) whose research interests include angiogenesis, extracellular matrix remodeling and microenvironmental effects on tumor biology; D. Roberts (NCI Bethesda) who is interested in the regulation of cell function and gene expression by the extracellular matrix in tumor cells; T. Uede (Hokkaido University) whose main interest is to understand the role of matricellular proteins in inflammatory disorders.

I would also like to thank C. Kleer (Dept. of Pathology and Comprehensive Cancer Center, University of Michigan) and L. Rittié (Dept. of Dermatology, University of Michigan) who both accepted my invitation to join the JCCS editorial board.

We firmly believe that the expertise of the new JCCS editors will be extremely helpful to our scientific community and will provide even more opportunities for fruitful overlaps between neighboring fields.

Let me also highlight that JCCS is presently under review to obtain an official impact factor, and that the active participation of these new editors will effectively help to make our application more sound.

As a reminder, JCCS is available in both printed and electronic versions. The new presentation of JCCS which was written for the electronic version of the journal can be accessed at: http://www.springer.com/12079.

In this issue, our readers will find a brief report on the 7 th international workshop on the $\mathrm{CCN}$ family of genes that was held in Nice, last October. 
Although the report is not meant to disclose unpublished data that were presented at the meeting, it provides the general flavour of the talks.

Together with the abstracts that are also provided in the present issue, the report constitutes an introduction to the progress made in the fields where $\mathrm{CCN}$ proteins have been reported to play key roles.

In addition to the meeting report and abstracts, we also have included a manuscript written by one of the Springer Scholarship awardees.

Of course, as previously highlighted, JCCS is not only devoted to publish CCN-related manuscripts, but also aims to provide a unique medium to stimulate collaborative projects and generate new avenues in the cell communication and signaling research fields.

Thanks are due to the chairs of the different sessions for contributing to this report.

\section{The ICCNS scientific board}

Along the same line, it was also concluded that we needed to bring «new blood» into the scientific board of the ICCNS.

The 7th international workshop on the CCN family of genes provided the occasion to discuss various options in depth. The consensus that was reached called for an increase in the activities of the Scientific Board whose President M. Takigawa had been elected 4 years ago.

Upon my recommendation, the members of the Scientific Board all agreed that M. Takigawa be renewed with the hope that his retirement and release from heavy laboratory duties would provide the perfect conditions for M. Takigawa to stimulate and «boost» the scientific life within the ICCNS.

M. Takigawa accepted this challenging task.

In order to help him along the way, I have proposed to invite colleagues from other various fields to join the Scientific Advisory Board.

It is my great pleasure to acknowledge H. Attramadal, E. Calabrese, J. Campisi, M. Colombo, M. Herlyn, U. Smith, P. Trackman, A. Yamaguchi and K. Yokote who accepted my invitation.

K. Otha and A. Kudo were introduced by K. Katsube

Y. Okada and M. Miyazono responded positively to the invitation of M. Takigawa.
On behalf of the ICCNS members, let me welcome all these new colleagues who were happy to help and participate in the extended ICCNS Scientific Board.

We do hope that all these changes, both in the JCCS and ICCNS organization will lead to more interactions between fields in the area of cell communication and signaling and will help to make the next ICCNS meeting, scheduled for 2015 in Nice, even more successful.

\section{The meaning of a logo}

In ending this editorial address, I would like to briefly introduce our new Society logo.

After much thinking, Annick and myself felt that it was time for a change in the Society logo which had been generously provided to us many years ago by a young and talented designer by the name of L. Gabaron.

Having in mind the need for the Society to have a more inclusive global reach, as expressed above, both for JCCS and the ICCNS, our choice for the new logo was based on the following reasons :

The C C N letters which are the foundation of our acronym, are embedded and interlaced in a fashion that leads our association, the International CCN Society, in an open way.

Open to the future, open to new ideas, open to more collaborations and contacts....

$\mathrm{CCN}$ as Centralized Communication Network, but also as «Communication, Creativity and Novelty», our motto for the next years to come!

Let the Society logo stand for the reflection of our original contributions to Science and to the welfare of humankind.

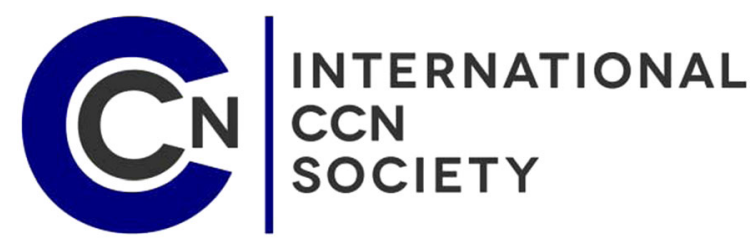

Bernard Perbal

President of the ICCNS

January, 31st, 2014

Acknowledgments I am grateful to Dr. H. Yeger and to Annick Perbal for critical reading of the manuscript and advice. 